University of New Hampshire

University of New Hampshire Scholars' Repository

$4-1-2000$

\title{
Satellite observation of El Niño effects on Amazon Forest phenology and productivity
}

Gregory P. Asner

Carnegie Institution for Science

Alan R. Townsend

NCAR

Rob Braswell

University of New Hampshire - Main Campus, rob.braswell@unh.edu

Follow this and additional works at: https://scholars.unh.edu/earthsci_facpub

\section{Recommended Citation}

G. P. Asner, A. R. Townsend, and B. H. Braswell, "Satellite observation of El Niño effects on Amazon forest phenology and productivity," Geophysical Research Letters, vol. 27, no. 7, pp. 981-984, Apr. 2000.

This Article is brought to you for free and open access by the Earth Sciences at University of New Hampshire Scholars' Repository. It has been accepted for inclusion in Earth Sciences Scholarship by an authorized administrator of University of New Hampshire Scholars' Repository. For more information, please contact Scholarly.Communication@unh.edu. 


\title{
Satellite observation of El Niño effects on Amazon forest phenology and productivity
}

\author{
Gregory P. Asner, Alan R. Townsend \\ University of Colorado, Boulder, Colorado
}

Bobby H. Braswell

Max Planck Institute for Biogeochemistry, Jena, Germany

\begin{abstract}
Climate variability may affect the functioning of Amazon moist tropical forests, and recent modeling analyses suggest that the carbon dynamics of the region vary interannually in response to precipitation and temperature anomalies. However, due to persistent orbital and atmospheric artifacts in the satellite record, remote sensing observations have not provided quantitative evidence that climate variation affects Amazon forest phenology or productivity. We developed a method to minimize and quantify non-biological artifacts in NOAA AVHRR satellite data, providing a record of estimated forest phenological variation from 1982-1993. The seasonal NDVI amplitude (a proxy for phenology) increased throughout much of the basin during El Niño periods when rainfall was anomalously low. Wetter La Nina episodes brought consistently smaller NDVI amplitudes. Using radiative transfer and terrestrial biogeochemical models driven by these satellite data, we estimate that canopy energy absorption and net primary production of Amazon forests varied interannually by as much as $21 \%$ and $18 \%$, respectively. These results provide large-scale observational evidence for interannual sensitivity to El Niffo of plant phenology and carbon flux in Amazon forests.
\end{abstract}

\section{Introduction}

Amazon moist tropical forests account for about $70-80 \mathrm{Pg}$ $\left(70-80 \times 10^{15} \mathrm{~g}\right)$ of the world's terrestrial carbon stocks and roughly 4-6 $\mathrm{Pg}(\sim 10 \%)$ of the annual net primary productivity (NPP) [Fearnside, 1997]. Because of the large carbon (C) pools and fluxes in this region, much attention has focused on the effects of land use on Amazon forest cover and C storage [Houghton et al., 2000], and on the potential feedbacks to regional and global climate [Shukla et al., 1990]. The role of climate in modulating interannual variability of Amazon forest phenology and NPP has received little attention until recently, yet this variation may be significant from both climatological and ecological perspectives. Uncertainties persist regarding spatial and temporal patterns of biosphereatmosphere $\mathrm{C}$ exchange, impeding global analyses of $\mathrm{CO}_{2}$ sources and sinks, and thus changes in climate forcing [Ciais et al., 1995]. Climate-driven phenology and NPP variability in the Amazon also has important implications for basin hydrology, river biology and biogeochemistry, trace gas fluxes, and patterns of land-use change.

The effects of the Amazon dry season (July-Nov.) on forest productivity have been recognized in both measurement and

Copyright 2000 by the American Geophysical Union.

Paper number 1999GL011113.

0094-8276/00/1999GL011113\$05.00 modeling studies [Jipp et al., 1998, Potter et al., 1998]. Phenological losses of canopy foliage are reduced during the dry season through forest deep root access to soil water reserves [Nepstad et al., 1994]. Nonetheless, field measurements do show that Amazon forest canopies respond to seasonal dry periods, with litterfall increases of $10-35 \%$ and decreases of leaf area index (LAI) of 15-25\% [ Jipp et al., 1998, Smith et al., 1998, Asner and Townsend, unpub. data].

There is now increasing focus on the effects of the El NinoSouthern Oscillation (ENSO), which is known to lengthen the dry season and decrease wet season rainfall in the Amazon basin [Marengo, 1992]. The 1983, 1987, and 1991/92 ENSO events varied in strength, but all resulted in anomalously low precipitation throughout much of the region (Fig. 1) [Costa and Foley, 1998, Nobre and Renno, 1985]. A recent ecosystem modeling effort indicated an interannual NPP variation of 3.8-5.7 $\mathrm{Pg} \mathrm{C} \mathrm{yr}^{-1}$ between 1980-1993 due to climate anomalies in the Amazon basin [Tian et al., 1998]. This study also suggested that the basin could vary from a net $\mathrm{CO}_{2}$ source of about $0.5 \mathrm{Pg} \mathrm{C} \mathrm{yr}{ }^{-1}$ to a net sink of similar magnitude. Independent observations are needed to evaluate estimates of a biological response to climate variation. Of the $30-50 \%$ interannual NPP variability reported by Tian et al. (1998), some portion of this variation may be detectable as forest canopy phenology. If true, this NPP variation may be resolved in multi-temporal satellite data, like that acquired by the NOAA TIROS satellites that carry the Advanced Very High Resolution Radiometer (AVHRR).

\section{Methods}

We used the NOAA/NASA Pathfinder AVHRR time series of surface reflectance data [James and Kalluri, 1994] to investigate Amazon forest responses to ENSO events from 1982-1993. The Pathfinder Normalized Difference Vegetation Index (NDVI) is a satellite metric used to detect relative changes in plant canopy "greenness", which is proportional to fractional photosynthetically active radiation absorption (fAPAR), functionally dependent upon LAI, and linked to NPP [Myneni and Williams, 1994, Tucker and Sellers, 1986]. However, the NDVI is also highly sensitive to atmospheric properties, such as clouds, water vapor and aerosols, and to solar illumination and satellite viewing geometry [Tanre et al., 1992, Privette et al., 1995]. These effects are only partially accounted for in the Pathfinder record through a temporal compositing routine that selects the highest NDVI values within 10 day time blocks [James and Kalluri, 1994]. Maximum value compositing is intended to minimize the effects of atmospheric constituents which almost universally decrease the NDVI [Tanre et al., 1992]. Pathfinder NDVI 
processing includes a series of empirical tests that utilize AVHRR optical and thermal channels to produce a cloud mask identifying contaminated pixels. However, several studies have found significant, persisting contamination by clouds and aerosols in AVHRR time series composites, and these contaminants are abundant in humid tropical regions [Holben et al., 1996]. In addition, the volcanic eruptions of $\mathrm{El}$ Chichon in 1982 and Mt. Pinatubo in 1991 injected sulfate aerosols into the stratosphere which decreased the NDVI for months [Vermote et al., 1997]. These effects cause apparent decreases in forest greenness which impede a quantitative interpretation of the NDVI time series of the Amazon basin.

Because of the limitations inherent in the AVHRR NDVI record, we developed a method to improve the NDVI screening for the Amazon basin and to provide error estimates on the NDVI values resulting from aerosols and orbital geometry. The data were first re-composited to monthly maximum values to further minimize atmospheric contaminants. Satellite pixels flagged as clear but located adjacent to those flagged as cloudy were found to have NDVI values that were statistically lower than other clear pixels. This occurs when small clouds or water vapor, which are in greater abundance near highly cloudy pixels, are present but do not reach the detection threshold developed for the Pathfinder time series. We therefore removed the cloud-flagged and the cloud-adjacent pixels from the analysis. Satellite pixels coincident with areas of deforestation and tropical savanna were identified using a land-cover map [Skole and Tucker, 1993] and were removed from the analysis. We then re-composited the data spatially by selecting the maximum NDVI value within $64 \times 64$ $\mathrm{km}$ grid cells. This further minimized the spatially heterogeneous effects of biomass burning aerosols which occur on scales of tens of kilometers [Holben et al., 1996].

Changes in solar illumination angle resulting from orbital drift of the AVHRR instrument occurred during the NOAA-9, -11 and -14 missions, and are evident in the Pathfinder composites as false upward NDVI trends from 1982-85, 1985-88, and 19881993 (Fig. 2) [Privette et al., 1995]. We developed a correction algorithm to normalize the NDVI values to a constant illumination and viewing geometry by coupling vegetation and atmosphere radiative transfer models [Vermote et al., 1996, Myneni and Asrar, 1993]. The coupled model was used to determine the angular derivative of surface-atmosphere reflectance resulting from changes in solar and view geometry, and then to normalize the NDVI to constant nadir geometry. Given a parameterization of the physical state of the canopy and atmosphere, the radiative transfer model yields the functional relationship between the solar/viewing geometry and reflectance [Myneni et al., 1997]. In forest canopies, the angular dependence of reflectance is primarily a function of canopy architecture [Gastellu-Etchegorry et al., 1999], which was assumed constant in the $64 \mathrm{~km}$ grid cells. We did not assume constant forest canopy LAI or foliar properties, both of which vary over time and space with forest canopy phenology and growth. Simultaneously, we quantified the effects of the $\mathrm{El}$ Chichon and Mt. Pinatubo eruptions on the NDVI using the radiative transfer model with estimates of stratospheric aerosol optical depth [Sato et al., 1993] and particulate properties [Harrison and van Grieken, 1998]. A Monte Carlo approach was used to propagate uncertainty in the estimated atmosphere and vegetation parameters in the model. This analysis yielded a revised NDVI time series with a range of possible errors from the orbital drift and volcanic aerosols (Fig. 2).

\section{Results and Discussion}

The southeastern Amazon basin, which experiences a stronger seasonal rainfall cycle and greater interannual precipitation variation (Fig. 1), had significantly greater NDVI (phenological) variability than the consistently wetter northwest region (Fig. 2). ENSO periods (1982/83, 1987, 1991/92) resulted in sharp increases in the amplitude of the seasonal cycle of NDVI (and thus fAPAR) values, most of which could be accounted for by negative NDVI anomalies during the dry season (Fig. 3a). This indicates stronger dryseason decreases in canopy greenness resulting from losses of canopy leaf area and decreased foliar chlorophyll activity and water concentration [Bohlman et al., 1998]. Monthly NDVI values were highest and the seasonal NDVI amplitude was lowest during La Nir̃a episodes (1984, 1988-89), when increased trade winds bring more rainfall to the Amazon basin (Fig. 1) [Marengo, 1992]. Dampening of the NDVI amplitude indicates increased canopy foliar content and lower foliar stress in the dry season during these wetter years. These results strongly suggest that Amazon forest phenology is responsive to rainfall variation on seasonal and interannual time scales.

Patterns in the seasonal NDVI cycle provide new insight to temporal variation in forest phenology, but they also provide a means to simulate ENSO impacts on Amazon forest productivity. Several studies have shown that the annual integral NDVI is proportional to NPP [Field et al., 1995, Tucker and Sellers, 1986]. We modeled Amazon forest productivity using the NPP algorithm from the CASA biosphere model [Field et al., 1995] coupled to a canopy radiative transfer model that accounts for the small, but functionally important asymptotic relationship between NDVI and canopy energy absorption in dense vegetation [Asner and Wessman, 1997]. In addition to the NDVI, CASA also required inputs of climate [Jones, 1994, Costa and Foley, 1998], soil texture [Potter et al., 1998], and an estimate of maximum light use efficiency of tropical forest species [Field et al., 1995]. Model results indicated a basin-level interannual NPP variation of 4.2-4.8 $\mathrm{Pg} \mathrm{C} \mathrm{yr}^{-1}$ (using mean NDVI values from Fig. 2) with the largest NPP decreases in anomalously dry years (Fig. 3b). Our NPP estimates were close to the lower bound estimates provided of Tian et al. (1998).

\section{Conclusions}

Data on atmospheric $\mathrm{CO}_{2}$ and its isotopes, when combined with atmospheric tracer models, provide observational evidence that tropical ecosystems may be an important driver of interannual variability in atmospheric $\mathrm{CO}_{2}$. At the global scale, Keeling et al. (1995) estimated that the two strongest periods of $\mathrm{CO}_{2}$ release between 1978 and 1994 correspond with the two ENSO events in the 1980's. Since then, two recent analyses indicated that the tropics play a major role in driving interannual changes in atmospheric $\mathrm{CO}_{2}$ [Gerard et al., 1999, Rayner et al., 1999], and Rayner et al.'s analysis showed that ENSO years are associated with anomalously high releases of $\mathrm{CO}_{2}$ from land in the tropics. All of these analyses were based upon atmospheric observations, from which biospheric behavior is inferred. In this paper, we have presented large-scale observational evidence of variation in the terrestrial tropics, evidence which generally supports the conclusions based on atmospheric data as well as the modeled estimates of plant productivity response to ENSO.

Our estimate of a $0.6 \mathrm{Pg}$ variation in Amazon NPP is a non-trivial fraction of the global variation shown in the Keeling et al. (1995) analysis, and this fraction is only that due to variability in undisturbed Amazonian ecosystems. However, we stress that while the remote sensing results 


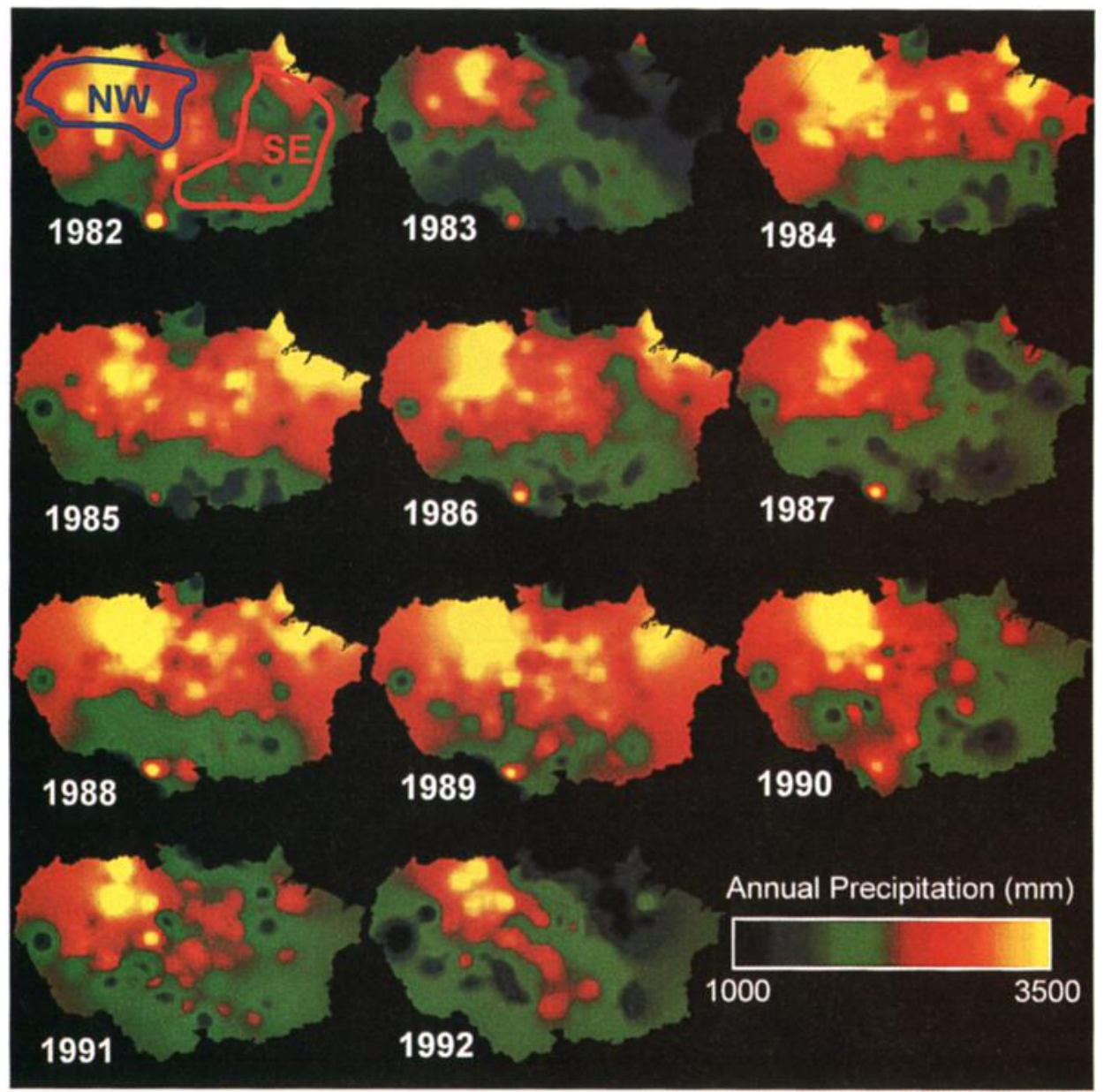

Figure 1. Interannual precipitation variability in the Amazon basin: ENSO periods (1983, 1987, 1991-1992) can be linked to decreased rainfall, especially in the southeast region of the basin. These maps were compiled and spatially interpolated from daily precipitation data collected from rainfall stations throughout the region [Costa and Foley, 1998]. Two contrasting regions (northwest and southeast) are delineated for subsequent analyses.

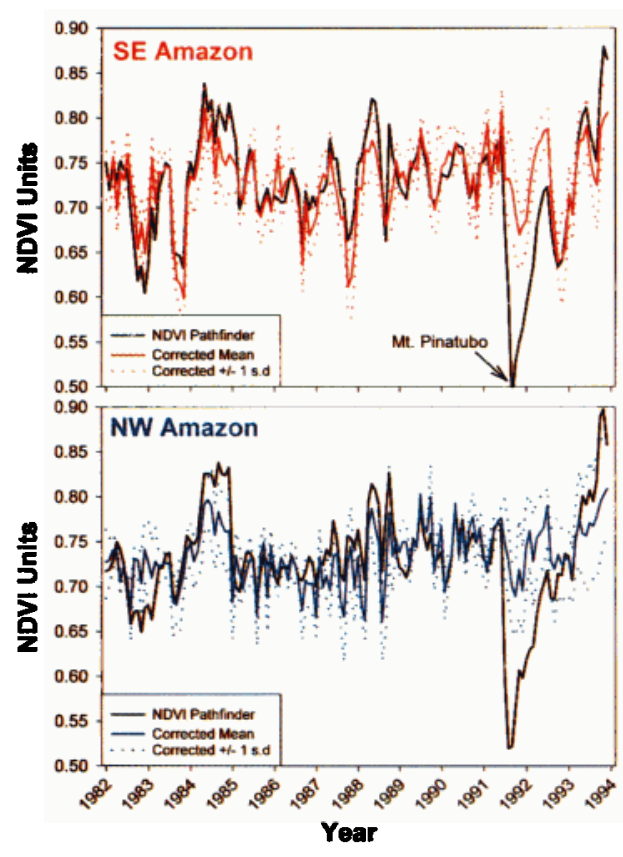

presented here suggest significant climate-driven variability in Amazonian phenology, errors in vegetation trends inferred from the record can be only approximately quantified because insufficient spectral and angular information is contained in the AVHRR measurements. Much of this difficulty will be resolved by the NASA EOS Terra satellite, which is designed to improve biospheric monitoring through improved sensor calibration, atmospheric corrections and biophysical modei integration [Running et al., 1994].

Figure 2. Time series NDVI data of southeast (top panel) and northwest (lower panel) Amazon regions (from Fig. 1). Black lines indicate mean NDVI time series of southeast (northwest) Amazon without aerosol and solar-viewing geometry correction. Red (blue) lines show corrected record with $+/-1$ std. dev. error resulting from uncertainties in the radiative transfer model inputs (e.g., aerosol optical depth, canopy architecture) used to account for stratospheric aerosols and geometry. 


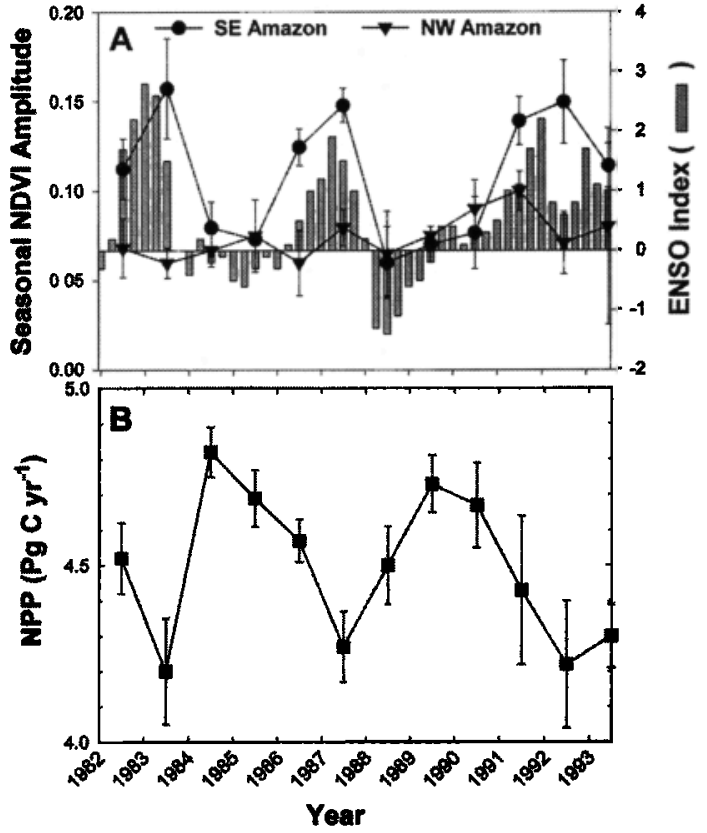

Figure 3. (A) Amplitude of seasonal NDVI cycle from 19821993 for the southeast (circles) and northwest (triangles) Amazon. Vertical gray bars show the NOAA Multivariate ENSO Index [Wolter and Timlin, 1993]: positive values indicate strength of $\mathrm{El}$ Nifo events; negative values indicate La Nifia episodes. (B) Interannual variation in NPP of the Amazon basin from 1982-1992 calculated using the CASA biosphere model and a canopy radiative transfer model (black squares; error bars = 1 std. dev. in NDVI estimate).

Acknowledgments. We thank R. Myneni and E. Vermote for providing radiative transfer code and $\mathrm{C}$. Field for the CASA code. This work was supported by NASA NIP grant NAG5-8709 to G. Asner and NASA NIP grant NAGW-5253 to A. Townsend.

\section{References}

Asner, G.P., C.A. Wessman, Scaling PAR absorption from the leaf to landscape level in spatially heterogeneous ecosystems, Ecol. Mod., 103, 81-97, 1997.

Bohlman, S.A., J.B. Adams, D.L. Peterson, Seasonal foliage changes in the Eastem Amazon Basin detected from Landsat Thematic Mapper satellite images, Biotropica, 30, 376-393, 1998.

Ciais, $\mathrm{P}_{\text {., }}$ et al., A large northern hemisphere $\mathrm{CO}_{2}$ sink indicated by the ${ }^{i 3} \mathrm{C} /{ }^{12} \mathrm{C}$ ratio of atmospheric $\mathrm{CO}_{2}$, Science, 269, 1098-1102, 1995.

Costa, M.H., J.A. Foley, A comparison of precipitation datasets for the Amazon basin, Geophys. Res. Let. 25, 155-158, 1998.

Fearnside, P.M., Carbon emissions and sequestration by forests: case studies of developing countries, Clim. Change, 35, 263-277, 1997.

Field, C.B., et al., Global net primary production: combining ecology and remote sensing, Rem. Sens. Environ., 51, 74-88, 1995.

Gastellu-Etchegorry, J.P., P. Guillevic, M. Leroy, Modeling BRF and radiation regime of boreal and tropical forests: I. BRF, Rem. Sens. Environ., 68, 281-297, 1999.

Gerard, J.C., et al., The interannual change of atmospheric $\mathrm{CO}_{2}$ : contribution of subtropical ecosystems?, Geophys. Res. Let., 26, 243-246, 1999.

Harrison, R.M., R.E. van Grieken, Atmospheric Particles, John Wiley and Sons, New York, 1998.

Holben, B.N., et al., Effect of dry-season biomass burning on Amazon basin aerosal concentrations and optical properties, 1992-1994, J. Geophys. Res., 101, 19465-19478, 1996.

Houghton, R.A, et al., Annual fluxes of $\mathrm{C}$ from deforestation and regrowth in the Brazilian amazon, Nature, 403, 301-304, 2000.
James, M.E., S.N.V. Kalluri, The Pathfinder AVHRR land data set: an improved coarse resolution data set for terrestrial monitoring, Int'l J. Rem. Sens., 15, 3347-3364, 1994.

Jipp, P.H., et al., Deep soil moisture storage and transpiration in forests and pastures of seasonally-dry Amazonia, Clim. Change, 39, 395-412, 1998.

Jones, P.D., Hemispheric surface air temperature variations: a reanalysis and an update to 1993, J. Clim., 7, 1794-1802, 1994.

Keeling, C.D., et al., Interannual extremes in the rate of rise of atmospheric carbon dioxide since 1980 , Nature, 375, 666-670, 1995.

Marengo, J.A., Interannual variability of surface climate in the Amazon basin, Int'l J. Clim., 12, 853-863, 1992.

Myneni, R.B., G. Asrar, Radiative transfer in three-dimensional atmosphere-vegetation media, J. Quant. Spectrosc. Rad. Transfer, 49, 585-598, 1993.

Myneni, R.B., D.L. Williams, On the relationship between fAPAR and NDVI, Rem. Sens. Environ., 49, 200-209, 1994.

Nepstad, D., et al., The role of deep roots in the hydrological and carbon cycles of Amazonian forests and pastures, Nature, 372, 666-669, 1994.

Nobre, C.A., N.O. Renno, Droughts and floods in South America due to the 1982-83 El Niño-Southern Oscillation episode, Proc. Conf. Hurricanes Trop. Meteor., 131-133, 1985.

Potter, C.S., et al., Regional application of an ecosystem production model for studies of biogeochemistry in Brazilian Amazonia, Glob. Change Biol., 4, 315-334, 1998.

Privette, J.L., et al., Effects of orbital drift on Advanced Very High Resolution Radiometer products: normalized difference vegetation index and sea surface temperature, Rem. Sens. Environ., 53, 164-171, 1995.

Rayner, P.J., et al., The relationship between tropical $\mathrm{CO}_{2}$ fluxes and the El Nino-Southern Oscillation, Geophys. Res. Let., 26, 493496, 1999.

Running, S.W., et al., Terrestrial remote sensing science and algorithms planned for EOS/MODIS, Int'l J. Rem. Sens., 15, 3587-3602, 1994.

Sato, M., et al., Stratospheric aerosol optical depth, 1850-1990, J. Geophys. Res., 98, 22987-22994, 1993.

Shukla, J., et al., Amazon deforestation and climate change, Science, 247, 1322-1325, 1990.

Skole, D., C.J. Tucker, Tropical deforestation and habitat fragmentation in the Amazon: satellite data from 1978-1988, Science, 260, 1905-1910, 1993

Smith, K., et al., Litterfall and nitrogen-use efficiency of plantations and primary forest in the eastern Brazilian Amazon, For. Ecol. Manage., 109, 209-220, 1998.

Tanre, D., et al., Atmospheric correction algorithm for NOAAAVHRR products: theory and application, IEEE Trans. Geosci. Rem. Sens., 30, 231-246, 1992.

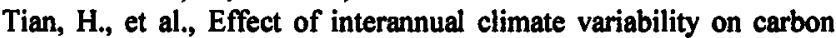
storage in Amazonian ecosystems, Nature, 396, 664-667, 1998.

Tucker, C.J., P.J. Sellers, Satellite remote sensing of primary production, Int'l J. Rem. Sens., 7, 1395-1416, 1986.

Vermote, E.F., et al., Data pre-processing: stratospheric aetosol perturbing effect on the remote sensing of vegetation: correction method for the composite NDVI after the Pinatubo eruption, Rem. Sens. Rev., 15, 7-21, 1997.

Vermote, E.F., et al., Second simulation of the satellite signal in the solar spectrum, 6S: an overview, IEEE Trans. Geosci. Rem. Sens., 35, 675-699, 1996.

Wolter, K., M.S. Timlin, Monitoring ENSO in COADS with a seasonally adjusted principal component index, Proc. 17th Clim. Diagnost. Wkshp., Norman, Oklahoma, 1993.

G. Asner, Geological Sciences and Environmental Studies, University of Colorado, Boulder, CO 80309 (email: asner@ colorado.edu).

A. Townsend, INSTAAR and EPO Biology, University of Colorado, Boulder, CO 80309 (email: alan.townsend@oolorado.edu)

B. Braswell, Max Planck Institute for Biogeochemistry, Jena, Germany (email: braswell@bgc-jena.mpg.de)

(Received September 28, 1999; revised February 4, 1999; accepted February 8, 2000.) 